\title{
Lucia Wald, Progresul în limbă. Scurtă istorie a limbajului. Ediția a II-a, revăzută. Text îngrijit, notă asupra ediției și prefaţă de Petre Gheorghe Bârlea, Editura Universității „Alexandru Ioan Cuza”, Iași, 2017, 346 p.
}

\author{
Adina Chirilă ${ }^{1 *}$, Francisc Gafton ${ }^{2}$ \\ ${ }^{1}$ Faculty of Letters, History and Theology, West University, Bd. Vasile Pârvan 4, 300223 Timișoara, Romania \\ ${ }^{2}$ Faculty of Letters, "Alexandru Ioan Cuza" University, Bd. Carol I 11, 700506 Iași, Romania
}

Republishing a book almost always rises questions regarding the mobile and the utility of such an act. Undoubtedly, the present case is that of a Disciple's rightful homage to his Master. Even so, Progresul in limbă [The Progress in Language] has two major virtues that converts the honorific gesture into a necessary scientific act. It is only natural that each and every generation tends to believe that the knowledge of the past has been surpassed by that of the present, that all that was worthy of keeping was kept and improved; but half a century means two generations, and, for many a piece of knowledge, enough time to be forgotten, misunderstood, or overcome by others, not necessarily more valuable. Although used for several decades now, the book has many a feature still capable of making it a guiding text, for it stands for more than a critical-now enriched-presentation of the history of some ideas.

On the other hand, it is equally natural that the landscape of scientific beliefs and expectations change in time, under the influence of cumulated practices and, consequently, of achievements in various fields; so that, republishing a book may secure a more fruitful position for it in the intellect of new readers, prepared differently from those contemporary with the writing of the book. Generally speaking, the humanistic perspective on what constitutes the truth is accompanied by two attitudes: one that, while formulating hypothesis, does it under the rigorous empirical rules, in search of the objective and, as far as possible, immutable truths; and one that regards the science as a medium for various ideologies, as a cultural construct, "in the spirit of the epoch". Once written and an asset of the intellectual community, a text serves either a party or the other, yet a context in which the latter is weaker can't be but auspicious for the text's value.

Justified by the ascertaining of a deficiency in the expected reader or/and called by a new-more comprehensible-frame of scientific inquires, to publish anew Lucia Wald's book is a waited for act. Through Petre Gheorghe Bârlea's extensive and minute Preface (p. 13-58), this new edition also settles anew the problems tackled by the author almost fifty years ago (1956-1968), in the field of linguistic research (associated, more and more lately, with cognitive, anthropological, genetical, etc. studies) of the day.

To Lucia Wald's theory, the history of the research on language transformation (see Chapter I, Istoricul conceptiilor despre progresul limbii [The history of the beliefs about the language progress] p. 59-103) serves as solid foundation; but it also consists of parts that ought to be abandoned. That is the case, e.g., of O. Jespersen, who, on the one hand, proclaimed the superiority of modern languages based solely on their analytical aspect-which he absolutized-, when, in reality, the evolution of languages (here understood as progress) is a more complex process, that admits considerable variations from one language to another; yet, on the other hand, the Danish linguist is one of the first who have argued their hypothesis with sets of fair propositions (we ought to say, however, that those of Jespersen were only partial) and with large linguistic material, thus inspiring the conviction that the progress in language can be objectively determined, although not entirely through similar means (cf. Ch. Bally - skeptical about the existence of any objective criterion for the evaluation of the "quality" of a language, in successive periods). With $\mathrm{K}$. Vossler, the rejection is altogether inevitable, if

\footnotetext{
*Email address: chiriladina@yahoo.com.
} 
one observes the meaning he attached to progress, namely 'change' - brought about by any innovation of an individual, that would come to be adopted by the community; but it is precisely this type of meaning that stands against the premises adopted and argued by Wald (see Chapter II, Consideraţii generale [General observations],p. 105-122): "[n]ot all that is new is also progressive, the post hoc ergo melius hoc thesis is not always applicable. For there are changes that do not affect the quality or that unnecessary complicate the system"; and "the notion of 'progress' cannot be substituted by that of evolution. Within the framework of a phenomenon's evolution, changes occur towards its progress or regress, or that do not alter its quality at all. The progress is only one side of the evolution, namely the one that expresses the passing from a certain quality to a superior one.

With respect to language, as well, it is obvious that one cannot take any given change as a sign of its progress or regress. One cannot assume that languages preserve their quality over time, unchanged, either, as if the changes they met were completely superfluous" (p. 107, emphasis added, A.C. \& F.G.).

The clarification is crucial. First of all, for the coherence of the task itself: that of answering the main question of the book - is there a progress in language? (alongside of its corollary: how could one determine the progress' ways of manifestation?). Secondly, the distinction states the boundaries of the concept of evolution observed by the author and which must as such be well assimilated by the present-day reader. For the latter is no longer aware of the scientific context prepared and shaped by the linguists of the $19^{\text {th }}$ and $20^{\text {th }}$ centuries only, but is geared in the present dynamics of science as well a science that tends to understands the question of language evolution (cf. the evolutionary linguistics) as the question regarding the apparition of this new kind of language at beings that would be called Homo sapiens, in connection with the emergence of a new way of thinking, and on the basis of other, older from the point of view of general evolution - systems.

If the non-identity between evolution and progress is a fact, it fallows that the triad by which the evolution exists-namely: a) increase in the number of units on each level of the language, b) qualitative transformation of their content, and c) strengthening the systematic character of each language level and of the language as a whole (p. 115)-does not func- tion exactly and entirely with the progress. The examination of the facts that may point out the real progress in language observes criteria that are established almost "on the fly", since "they [...] ought to result from the taking into consideration the specific functions of language and from the analysis of the linguistic material" (p. 112). Moreover, this examination must be open to the possibility that one of the criteria be irrelevant, or, at best, less important than presumed a priori, or even deceiving (as in the case of the quantitative criterion in measuring the progress provided by the morphology of language).

The search for the direction of evolution and of the particular ways in which it operates begins by analysing the phonologic aspect of the language (see Chapter III, Progresul in fonetică [The progress in phonology], p. 123-146). First, by critically synthesizing the studies and conclusions of linguists concerned, on the one hand, with the problem of the chronology of the phonologic inventory, and, on the other hand, with the problem of the phonological system and of its internal dynamics, Lucia Wald concludes that neither the first aspect (whose laws are conditioned by physiological factors), nor the second one (which never reaches a state of perfect equilibrium, but passes through successive stages of harmony and disharmony) does not offer the proof of an actual progress. However, an ascending spiral evolution (p. 146) can be seen in the history of the sound pattern of words relating to their semantic content; thus, Wald talks of three stages: 1) when predominant is the motivated aspect of the sound pattern; 2) when, on the contrary, predominant is the unmotivated aspect, and 3) when predominant is a "relative motivation" (Wald accepts here Saussure's description), abstract and systematic, in which the motivation concerns the system, not the extralinguistic reality. Language achieves a superior state, defined by its capacity to create "words that, while capable of conveying an abstract meaning, offer the advantage of being easily understood and memorized, and easily reconstructed by the speaker" (p. 146).

With the vocabulary (v. Chapter VI, Progresul in vocabular [The progress in vocabulary], p. 147175), the quantitative stride (resulting from both the acquisition and loss of words - against cultural and social change) is, again, the weakest criterion in establishing the degree of progress in language. It 
must be associated with the second criterion, that of the quality of words, of their semantic force. Otherwise, a language that possesses a multitude of terms for a multitude of concrete details, but the one generic term, would occupy a higher position on the scale of evolution, over a language that possesses the one, without concern for the multitude (or, in any case, that has found the solution of designating the concrete details through combinations of more general terms). The issue concerns the capacity to surpass perceptual analysis, and to apply logic analysis and to express it. The author uses once again the analogy from the previous chapter, placing the language on three ascending positions: " $[t]$ he evolution of meanings appears as a spiral: from the general undifferentiated and vague, to the exact notation of the concrete, and then to the logic abstract" (p. 156; see also p. 166, with a subtle note: "[o]ne might say that, because of the quantity of abstract words that it contains, the main lexical fund reflects more accurately than the whole vocabulary a community's stage of development, since the former shows not how many abstract words a language possesses, but what kind of abstract notions have become current among the speakers"). And she builds her theory on facts related to contemporary tribal languages and ancient Indo-European languages. Finally, Wald emphasizes that the systematicity of the vocabulary and its organized aspect are the two reliable indicators of the progress in present-day languages - a fact that one can agree with, at least to a point, in the case of the ancient languages as well. Actually, at the end of the chapter, the author argues in favour of the validity of the third criterion - which shows the evolution of language from compounding to derivation - by analysing the case of Latin.

The morphology rises the most complex problematic (see Chapter V, Progresul in morfologie [The progress in morphology] p. 177-255), since this language level demands the diachronic examination of several microsystems (noun, adjective, pronoun, article, verb, etc.) in relation with the vocabulary and the syntax. Nevertheless, paradoxically, morphology offers the weakest argument for evolution, or for the progress in language. The difficulty of the task is enhanced by the fact that morphology is, in itself, the linguistic compartment that differentiates languages the most, thus hindering the coming to unitary and uniform conclusions. Two or more contemporary related languages, that share the same structural features and are on the same level of development, may display several morphological features that are very different, even opposite. Although, on the whole, it can be assumed that the same laws and general principles of linguistic change operate in any language, independently of any particular language specific causation (e.g., optimization is a universal and permanent principle), the rhythm in which they operate is dissimilar and, therefore, differentiating. However, one can safely assume that the ascending direction in evolution is provided by the tendency "to abstract the content of [morphological] categories-operation that reflects the ceaseless evolution of thinking-, and to systematize these categories" (p. 255).

On the contrary, one can more easily discover the direction of the evolution in syntax (see Chapter VI, Progresul in sintaxă [The progress in syntax], p. 257286). Because it is closely and directly related to thinking, the syntax mirrors its degree of abstracting and complexity; thus, if we are to admit the existence of a progress in thinking, the central question of the book will receive an immediate positive answer concerning the syntax. But with Lucia Wald it comes after a demonstration conducted according to the same rules and principles applied in the study of phonology, vocabulary and morphology. So, "an increased number of [syntactic] relations, their greater frequency and their greater variety force the language towards a more severe organizing process, which means government in sentence and hypotaxis in phrase. From simple syntactic forms (words' order and intonation), to abstract morphological forms, like those of inflexion and agreement, and to specialized syntactic forms (prepositions and conjunctions), the syntax of a language records the evolution of thinking from the concrete to the abstract, and to the logical concrete - a phase superior to the abstract, since it includes both the abstract and the specifying" (p. 283).

Although many valuable works have been published on the subject of the causal explanations for the principles of change in phonology, morphology, syntax, diachronic semantics, etc., the causes of language change - which, in some cases, mark the actual progress of a language - are not easily identifiable, and more often than not one wanders about why a certain factor takes action before all other possible factors of change, with results that may involve 
optimization in one aspect, and the opposite in another. Lucia Wald tries to systematize these causes (see Chapter VII, Problema progresului din punctul de vedere al antinomiilor lingvistice [The problem of progress from the point of view of the linguistic antinomies], p. 287-311) and to outline the complex mechanism which, when affecting the language at one level, produces changes at the other levels as well. The main force that triggers the language dynamics would be the permanent tension (and equilibrium) between the need to transmit a content clearly and exactly, and the tendency to simplify the form - a situation of which the speaker (or the entire generation of speakers) is not completely aware. Alongside this force, there are several other factors, that impose different paces of evolution, without threatening the essential continuity (changes are gradual in a speech community): social and historical factors, contact between languages, geographic factors, cultural factors, the language system itself, etc. Wald concludes her thesis about the progress in language by saying that "the spontaneity does not reign in language, otherwise there would be chaos; nor does the finality, otherwise all changes would be made in the direction of progress. Under the pressure of communication needs, language keeps changing permanently, according to its inner objective laws and to the conscious intervention that is aware of these laws" (p. 310).

The chapter that precedes the final considerations deals with the other direction of evolution, namely the degradation of language (see Chapter VIII, Regresul in limbă [The regress in language], p. 313-320) - a phenomenon not less natural than the progress. Usually, the degradation or the regress represents a phase of lack of balance during the evolution of a language, against which the language itself comes with its tendency towards progress, through systematization, for example. So, sooner or later, the language manages to restore the equilibrium. There are instances, though, when the continuous process of degradation ends with the language's death. Once again, Wald investigates the phenomenon objectively, and points out its causes: accidents of different kinds, unfavourable historical conditions, the invasive force of other linguistic codes, reduction of the social value of the language, rarefaction of the speech community, etc.

Briefly, in the last chapter of the book (see
Chapter IX, Incheiere [Closing], p. 321-326), Lucia Wald reaffirms her believes, which, on the one hand, have guided the present research, and, on the other hand, have emerged from her work: human language is in a permanent state of change; changes determine either the progress or the regress in language, or are simply neutral; the evolution of language (the progress or the regress) is an objective fact, that can be proved objectively; a given language does not evolve in a monotonous rhythm throughout its existence, and two different languages do not experience the same rhythms of evolution; the factors that shape the dynamics of language change are themselves historically conditioned, and are influenced by the specific structure of the language.

It seems that the most passionately defended idea is that " $[0]$ ne must hold that the progress of language - as of any other phenomenon-means a more plenary reaching of its essence. In the case of the language, its essence lies in its capacity to be the principal means for transmitting ideas. Thus, considering the evolution of a language from the point of view of the communication process, one must find progressive those transformations which permit a clearer formulation of ideas, and a faster and better transmission of them" (p. 322; see also p. 108, 113).

Guided by an exemplary positivism-it is, in fact, part of the motive of this book's existence: "is there progress in language evolution? And, if it was, how could its ways of manifestation be determined?" (p. 105, emphasis added, A.C. \& F.G.)-, Lucia Wald restrained from perpetuating or formulating ideas that could not have been objectively demonstrated. Thus, judgements like "more difficult" or "easier", unquantifiable, couldn't be but absent from the evaluation of the progressive value of certain linguistic facts (see p. 116), although they are auxiliary to the second element of the pair clarity - simplification. However, they might now be part of the demonstration, in the light of recent psycholinguistic experiments measuring processing time, error rate, etc.

Only by seeing reality as it is, evolving, and only observing its emergence, its development and its functioning, one can hope to gain an accurate, plenary and whole knowledge of it. Progresul în limbă 
[The Progress in Language] exhibits the amplitude of the processes through which the language functions as organ of thinking and instrument of society - a triad that follows the objective laws and reflects the Nature's unity of conception, and its products' unity of function.

The method that nurtures the working suits the general perspective: it is exhaustive, critical and historical. In this way, the result goes beyond the simple gathering of information and explanations, and teaches about the correct means of scientific investigation. In order to reach its end-to offer a knowledge of the reality as reality is-, science needs such a perspective and such a method; they ought to be kept in mind, and applied. Lucia Wald's book offers this much-needed model, and Petre Gheorghe Bârlea's edition is an implicit stimulus towards the applying of such a model. 